\title{
Hydraulic resistances of drain pipes
}

\section{J. Wesseling and F. Homma}

Instituut voor Cultuurtechniek en Waterhuishouding (I.C.W.), P.O. Box 35, Wageningen, The Netherlands

Received 21 September, 1966

\section{Summary}

Hydraulic resistance measurements with full flowing drainage pipes under pressure, show a straight line relationship between $\log \lambda$ and $\log$ Re. From this relation, resistance equations were derived showing higher exponents for $\mathbf{R}$ and $\mathbf{S}$ than are given in the normally used Manning formula. For plastic pipes the resistance depends on the quality of the perforations, while for clay tiles alignment is an important factor. This does not hold for corrugated pipes, the resistance of these pipes could be described by the Manning formula with $k_{\mathrm{M}}=71$.

For a constant inflow per unit length of drain an equation giving the relation between discharge, hydraulic head and length of the drain line was derived. When values of hydraulic head computed with this equation were compared with field data, the latter gave higher resistances for the pipes. Since from flow experiments with lateral inflow no influence of this on the apparent roughness of the pipes could be concluded, the higher losses under field conditions must be ascribed to alignment, quality of perforation or to silting of the lines.

Since under field conditions the flow resistance is higher than that computed from the described experiments, the given maximum allowable drained areas for certain types of pipes must be considered as theoretical values to which a reduction must be applied for field conditions.

Finally it was proved that the experiments covered a range of Reynolds numbers sufficient for practice.

\section{Introduction}

With an increasing use of relatively cheap small-diameter plastic drain tubes, it becomes more and more important to be informed about the hydraulic resistance of this type of pipes. Apart from the hydrological aspects of the use of small-diameter pipes (higher entrance resistance), the hydraulic properties will determine what area can be drained with a pipe of a given diameter. Inversely, one often wants to be informed what diameter of pipe must be used to drain a given area with a known design drainage coefficient.

The hydraulic design of a drainage system is nearly always based on the well-known Manning-formula:

$\mathrm{v}=k_{\mathrm{M}} \quad \mathrm{R}^{2 / 3} \mathrm{~S}^{1 / 2}$

where $\mathrm{v}=$ the flow velocity $(\mathrm{m} / \mathrm{sec}), \mathrm{R}=$ the hydraulic radius $(\mathrm{m}), \mathrm{S}=$ the hydraulic gradient $(\mathrm{m} / \mathrm{m})$ and $k_{\mathrm{M}}=$ the Manning-coefficient $\left(\mathrm{m}^{1 / 3} / \mathrm{sec}\right)$. 
For clay tiles Manning-coefficients of 50 to 75 are given dependent on wall-roughness of the tiles and the alignment (Yarnell and Woodward, 1920; Schewior-Press, 1958). Computations of $k_{\mathrm{M}}$-values from field data on discharge and hydraulic head show in general much smaller values, but the results vary widely for measurements pertaining to different discharges, even for the same line. Olbertz and Wertz (1962) point out that experimental results on hydraulic resistances of drain pipes always give a general equation:

$\mathrm{v}=\mathrm{CR}^{\mathrm{m}} \mathrm{S} \mathrm{n}$

with $\mathrm{m}$ and $\mathrm{n}$ larger than the values indicated in equation 1 . Such results may be found in Visser (1937), Blazhys (1965) and Brink and Nilsson (1965).

In an earlier article (Wesseling, 1964) nomographs for the hydraulic design of drain lines have been published. As far as it concerned clay tiles the nomograph was based on Manning's formula. For plastic lines a formula of the type of equation 2 was used. In order to check the basic formula, series of laboratory experiments on the hydraulic resistance of full flowing pipes have been carried out ${ }^{1}$. The results of these experiments were used to derive resistance equations for various types of pipes.

Since the obtained formulas showed certain discrepances with field data, a series of experiments with lateral inflow was carried out to see whether this influences the apparent roughness of the pipes.

In this article the results of both types of experiments are described. The derived resistance equations were checked with some field experiments. Finally tables for the maximum allowable area to be drained by pipes of various diameters are given.

\section{Materials and methods}

Hydraulic flow experiments were carried out with the following types of pipes:

a) Smooth rigid PVC-pipes with an outer diameter of $40 \mathrm{~mm}$ and a wall-thickness of $0.8 \mathrm{~mm}$.

b) The same type of pipe with longitudinal slits, constructed in such a way that nearly no material originating from the perforation was left inside the pipe (well perforated pipe).

c) The same type of pipe with perforations from which most of the material was left as hairs inside the pipe (badly perforated pipes).

d) Unperforated corrugated PVC pipes (Hegler system) of $40 \mathrm{~mm}$ outer diameter, having a wall thickness of about $0.3 \mathrm{~mm}$. The corrugations were in spirals and had a height and width of about $3 \mathrm{~mm}$.

e) The same type of pipe but with an outer diameter of $50 \mathrm{~mm}$.

As far as perforated pipes were used, the perforations were sealed by wrapping and cementing a strip of plastic sheet around the pipes.

The experiments were carried out in the Laboratory of Hydraulics of the Agricul-

1 The experiments were carried out with a grant of the Government Service for Land and Water Use. The authors are greatly indebted to ir. Van Someren of the Research Department of this Service for his help. 

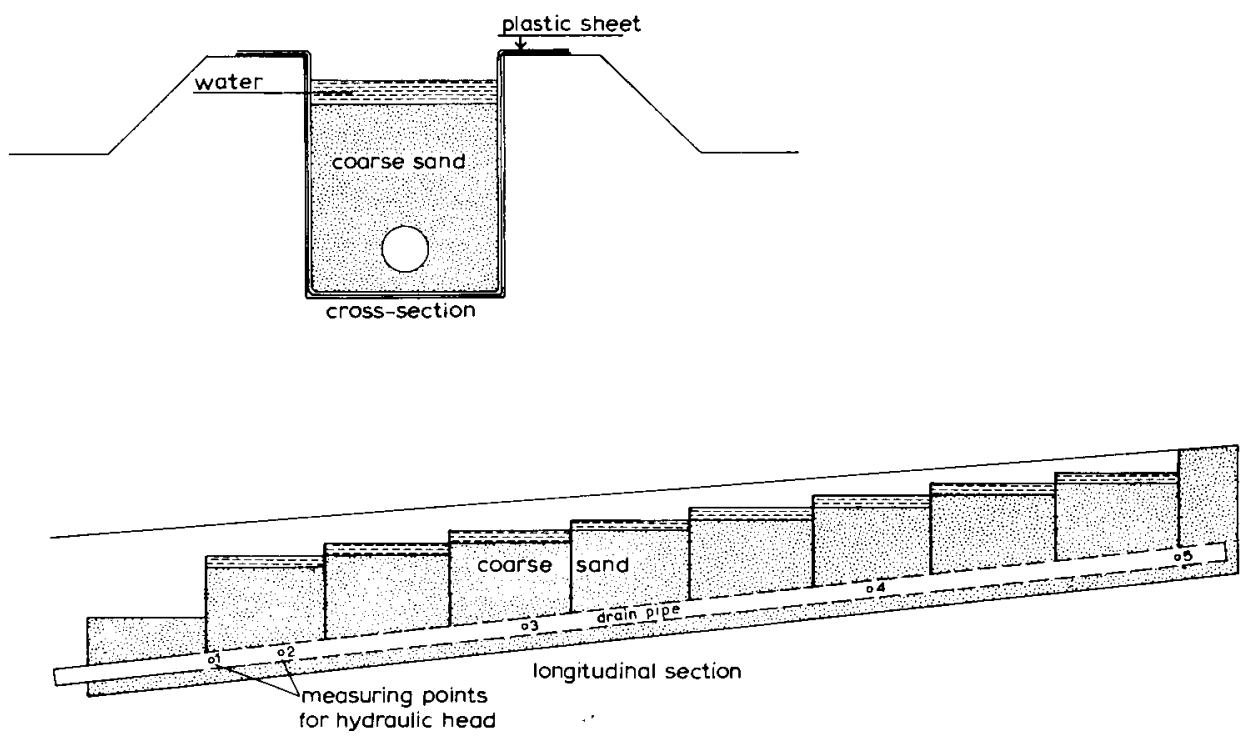

Fig. I Schematic representation of the experimental set up for flow experiments with lateral inflow.

tural University ${ }^{2}$. Lengths of $40 \mathrm{~m}$ of the pipes were mounted on a horizontal rack. Two measuring points were installed at about $5 \mathrm{~m}$ from each end and an additional one in the middle, leaving a test section of about $30 \mathrm{~m}$ length. The measuring points were connected with a central manometer pannel by means of plastic tubes, making direct readings of pressure differences possible. Discharges were measured either with the available measuring cistern or with an hydraulic balance.

Flow experiments with lateral inflow were carried out in a trench having a length of $45 \mathrm{~m}$, a depth of $25 \mathrm{~cm}$ and a width of $20 \mathrm{~cm}$. The bottom slope of the trench was chosen at 5 per thousand (Fig. 1). After sealing bottom and side walls of the trench with a plastic sheet, a $3-\mathrm{cm}$ thick layer of coarse sand was put in on which a $40 \mathrm{~mm}$ PVC drain pipe was installed. Except for the last $5 \mathrm{~m}$ of the pipe, which ended into an open ditch, the pipe had 4 rows of longitudinal slits and a sheet of glass fibre wrapped around it. Five measuring points were connected to a central manometer pannel by means of plastic tubes, and the top end of the pipe was closed with a rubber stopper. At each $5 \mathrm{~m}$ a partition was installed with the top $20 \mathrm{~cm}$ above the bottom of the trench. In order to prevent leakage of water past the partitions, the sides were sealed by cementing a sheet of plastic against partition and side wall of the trench. Then the trench was filled with coarse sand and water was added to the trench by means of a perforated pipe connected with a pump. The discharge of the pump was chosen in such a way that only a very small amount of water was flowing over the partitions (Fig. 2).

- The authors wish to thank Professor Krayenhoff van de Leur and ir. Pitlo for their cooporation and advice and mr. Knops for carrying out the measurements. 


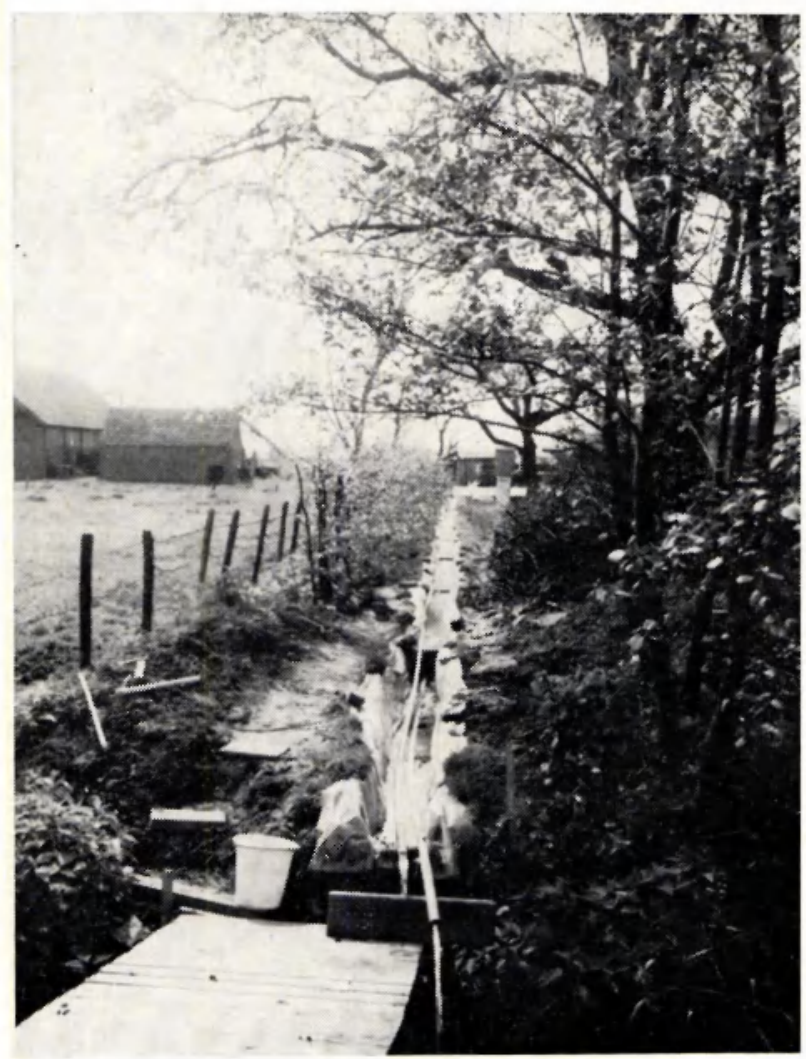

Fig. 2 The experimental set up for flow experiments with lateral inflow.

The discharge of the drain itself was changed by placing rubber stoppers with different openings in the bottom end of the pipe. As soon as stationnary flow occurred, hydraulic heads in the drain pipe were measured. In order to get a constant inflow per unit length of drain, the levels of the partitions were raised or lowered to such a degree, that the mean level of the free water surface in the trench was in agreement with the hydraulic head in the drain. After some time, the head measurements were repeated and a second adjustment of the partition heights was carried out. Generally satisfactory agreement between the gradient of the free water surface and the hydraulic gradient in the drain could be obtained after two adjustments.

\section{Results of the measurements}

The first type of experiments gave hydraulic heads for different flow velocities. These data have been used to compute the dimensionless friction factor $\lambda$ from the DarcyWeisbach equation: 
$\frac{\mathrm{z}}{\mathrm{L}}=\frac{\lambda}{\mathrm{D}} \frac{\mathrm{v}^{2}}{2 \mathrm{~g}}$

where $\mathrm{z}=$ loss in hydraulic head $(\mathrm{m}), \mathrm{L}=$ length of the test section $(\mathrm{m}), \mathrm{D}=$ inner diameter of pipe $(\mathrm{m}), \mathrm{v}=$ flow velocity $(\mathrm{m} / \mathrm{sec})$ and $\mathrm{g}=$ accelleration of gravity $\left(\mathrm{m} / \mathrm{sec}^{2}\right)$.

The obtained values for $\lambda$ were then plotted against the Reynolds number $\operatorname{Re}(=\mathrm{vD} / \nu)$.

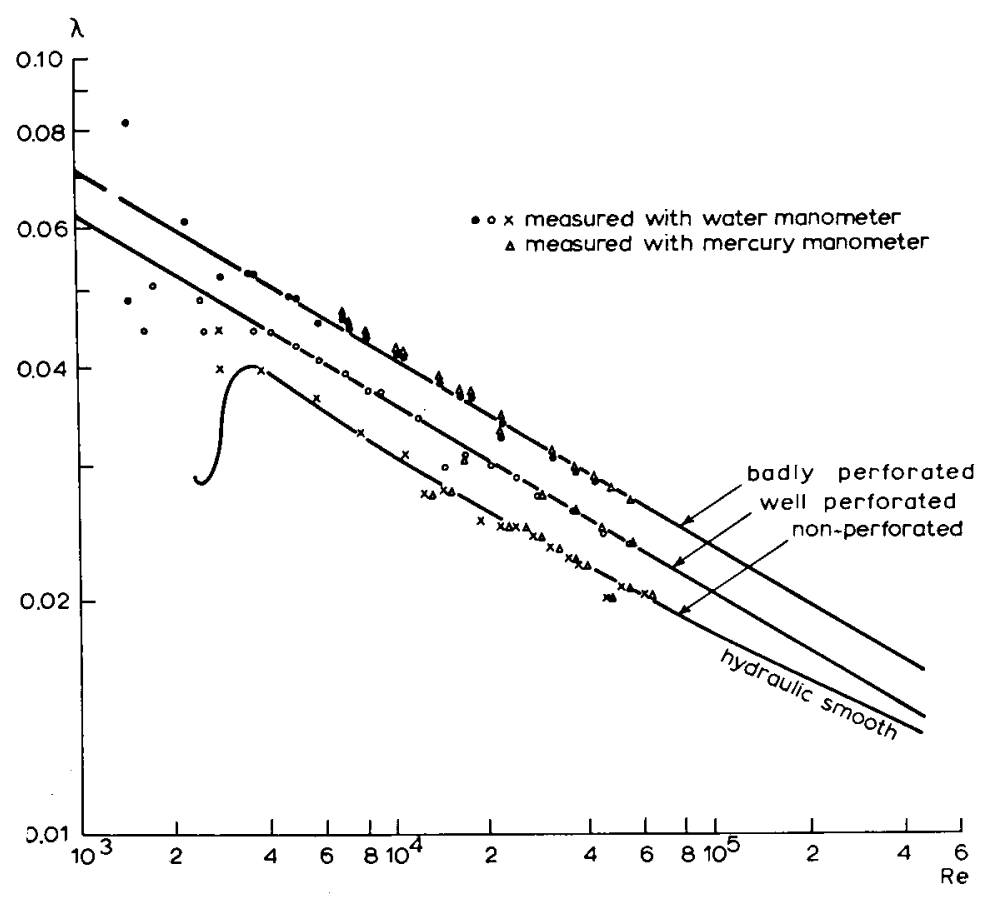

Fig. 3 Computed values of $\lambda$ obtained from measurements against Re for smooth plastic pipes. Lower line for hydraulic smooth pipes after Colebrook-White.

For smooth plastic pipes the result is given in Fig. 3. The full-drawn line through the points pertaining to the unperforated pipe is the line for hydraulic smooth pipes from Colebrook-White. For the perforated pipes this straight line apparently is shifted parallel, the shift being larger for badly perforated pipes. Later measurements on $50 \mathrm{~mm}$ clay tiles show that for that type of pipe $\lambda$ may be considered to be the same as that found here for well perforated plastic pipes ${ }^{3}$. Since the clay tiles used for these experiments were of good quality and were packed in a fire-hose, the results must be considered to be valid for an excellent alignment only.

Since a parallel shift occurs in the relation between $\log \lambda$ and $\log \mathrm{Re}$, the irregu-

3 These measurements have been carried out by Mr. Faber under supervision of the Laboratory for Hydraulics of the Agricultural University. The authors thank Mr. Pitlo and Mr. Faber for providing these data. 
larities caused by perforations and tile joints increase the apparent roughness of the drains acting as in an 'isolated roughness flow' (Morris, 1955).

Results, similar to those given in Fig. 3 were found by Blazhys (1965) and Treude (1964). The first-mentioned author gives lines which show a larger shift the poorer the alignment. From both authors the lines tend to flatten out for Reynolds numbers larger than $7 \times 10^{4}$ as the line for hydraulic smooth pipes in Fig. 3 does. It will be proved, however, that such high Reynolds numbers rarely occur in drainage, so for the relation between $\lambda$ and $\mathrm{Re}$ straight lines can be used as a very good approximation. The results for the corrugated pipes are given in Fig. 4. The lines in this figure represent $\lambda$-values for $\mathrm{D} / k=20$ after Colebrook-White. Such pipes seem to act like hydraulic rough pipes. Since it is difficult to obtain an exact value for the inner diameter of this type of pipes, the results will be less accurate.

The results of the experiments with lateral inflow will be discussed under The influence of lateral inflow since the treatment of the results is based on resistance formulas derived from the above experiments.
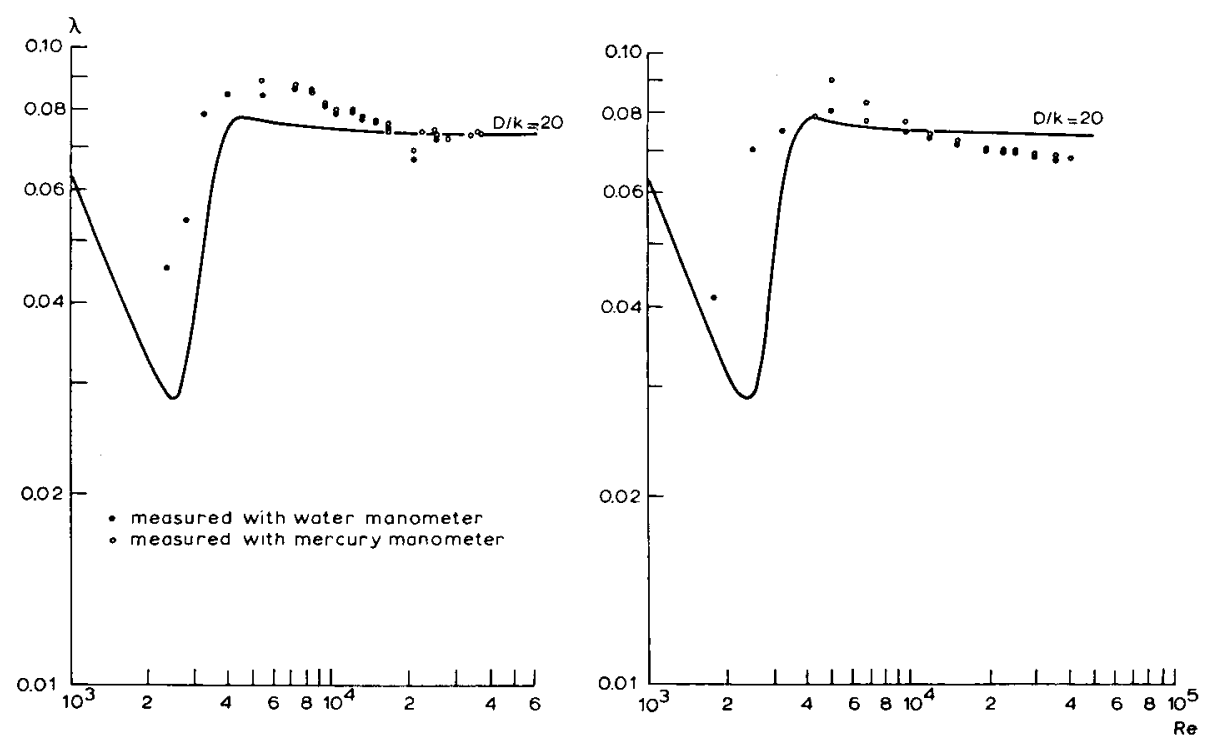

Fig. 4 Computed values of $\lambda$ obtained from measurements against Re for corrugated plastic pipes. Left hand figure for a $40 \mathrm{~mm}$ pipe, right hand figure for a $50 \mathrm{~mm}$ pipe. The curves are $\lambda$-values for $D / k=20$ after Colebrook-White.

\section{Derivation of resistance equations}

As has been pointed out above, the relation between $\log \lambda$ and $\log \operatorname{Re}$ may be considered as being of the straight line type for smooth pipes, and in the region of turbulent flow at least in the measured range up to $\operatorname{Re}$ is $6 \times 10^{4}$ to $7 \times 10^{4}$.

Assuming a shift of the lines parallel to that for hydraulic smooth pipes, the following relation holds: 
where $a$ is a measure for the shift of the line and henceforth for the irregularities near the perforations or tile joints. The experiments then give the following a-values:

Unperforated pipes $\quad a=0.3164$

Well perforated pipes $a=0.35$

Badly perforated pipes $\mathrm{a}=0.41$

It should be noted here that clay tiles with an excellent alignment agree with the wall perforated pipes. Some values derived from data given by Blazhys (1965) for clay tiles are:

\begin{tabular}{|c|c|c|c|}
\hline Carefully & laid pipes & $\mathrm{D}=50 \mathrm{~mm}$ & $\mathrm{a}=0.357$ \\
\hline & 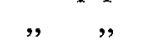 & $\mathrm{D}=75 \mathrm{~mm}$ & $a=0.340$ \\
\hline & ", & $\mathrm{D}=100 \mathrm{~mm}$ & $\mathrm{a}=0.322$ \\
\hline ad align & ment & $\mathrm{D}=200 \mathrm{~mm}$ & $a=0.447$ \\
\hline
\end{tabular}

The value for $50 \mathrm{~mm}$ clay tiles is in close agreement with the experiments described above. For larger pipes the a-value is decreasing in agreement with what can be expected, since for larger diameters a relatively smaller portion of the cross-section of the pipe is affected by irregularities near the joints.

Substitution of equation 4 into equation 3 , replacing $\operatorname{Re}$ by $v D / v$ and $R$ by $D / 4$ gives after some rearrangement:

$\mathrm{S}=\frac{\mathrm{z}}{\mathrm{L}}=26.3 \times 10^{-4} \mathrm{a} \mathrm{D}^{-4.75} \mathrm{Q}^{1.75}$

where $\nu$ is taken $1.31 \times 10^{-6} \mathrm{~m}^{2} / \mathrm{sec}$.

Substitution of an a-value equal to 0.3164 (unperforated plastic pipe) now gives:

$\mathrm{S}=\frac{\mathrm{z}}{\mathrm{L}}=8.33 \times 10^{-4} \mathrm{D}^{-4.75} \mathrm{Q}^{1.75}$

This equation can be converted into the general form given by equation 2 . The result then is:

$\mathrm{v}=198.2 \mathrm{R}^{0.714} \mathrm{~S}^{0.572}$

In this form a comparison with results obtained by other authors is given in Table 1. For corrugated pipes no straight line relationship between $\lambda$ and $\operatorname{Re}$ can be found from Fig. 4. Therefore the measured gradient was plotted against $Q$ (Fig. 5). The results for the corrugated pipes then form a straight line with a slope of 0.5 . Representing these results by the Manning formula one obtains:

$\mathrm{v}=71 \mathrm{R}^{2 / 3} \mathbf{S}^{1 / 2}$

For a similar type of pipe with diameters ranging from 38 to $91.8 \mathrm{~mm}$ Brink and Nilsson (1965) give:

$\mathrm{v}=77.5 \mathrm{R}^{0.665} \mathrm{~S}^{0.493}$ 
Table 1 Comparisons of resistance equations derived from data of various authors

Type of pipe, authors

Unperforated plastic pipes

Present experiments

Wavin (Wesseling, 1964)

Brink and Nilsson (1965)

Olbertz and Wertz (1962)

Olbertz and Wertz (1962)

Perforated plastic pipes

Present experiments (well perforated)

Present experiments (badly perforated)

Brink and Nilsson (1965)

Clay tiles

Present experiments

Visser (1937)

Blazhys (1965)

Blazhys (1965)

Blazhys (1965)

Blazhys (1965) (bad alignment)
Inner diameter of pipe, $D$ $(\mathrm{mm})$

$\begin{array}{llll}40 & \mathbf{v}=198.2 & \mathbf{R} 0.714 & \mathbf{S}^{0.572} \\ 40 & \mathrm{v}=181.2 & \mathbf{R} 0.705 & \mathbf{S}^{0.568} \\ 38.86 & \mathrm{v}=205.7 & \mathbf{R} 0.718 & \mathbf{S}^{0.570} \\ 36 & \mathrm{v}=126 & \mathbf{R} 0.667 & \mathbf{S}^{0.53} \\ 50 & \mathrm{v}=235 & \mathbf{R} 0.667 & \mathbf{S}^{0.63}\end{array}$

$\begin{array}{llll}40 & \mathrm{v}=186.7 & \mathrm{R}^{0.714} & \mathbf{S}^{0.572} \\ 40 & \mathrm{v}=168.6 & \mathbf{R}^{0.714} & \mathbf{S}^{0.572} \\ 38.86 & \mathrm{v}=200.2 & \mathrm{R}^{0.718} & \mathbf{S}^{0.570}\end{array}$

* Computed from $\lambda$-values or converted from an other type of equation

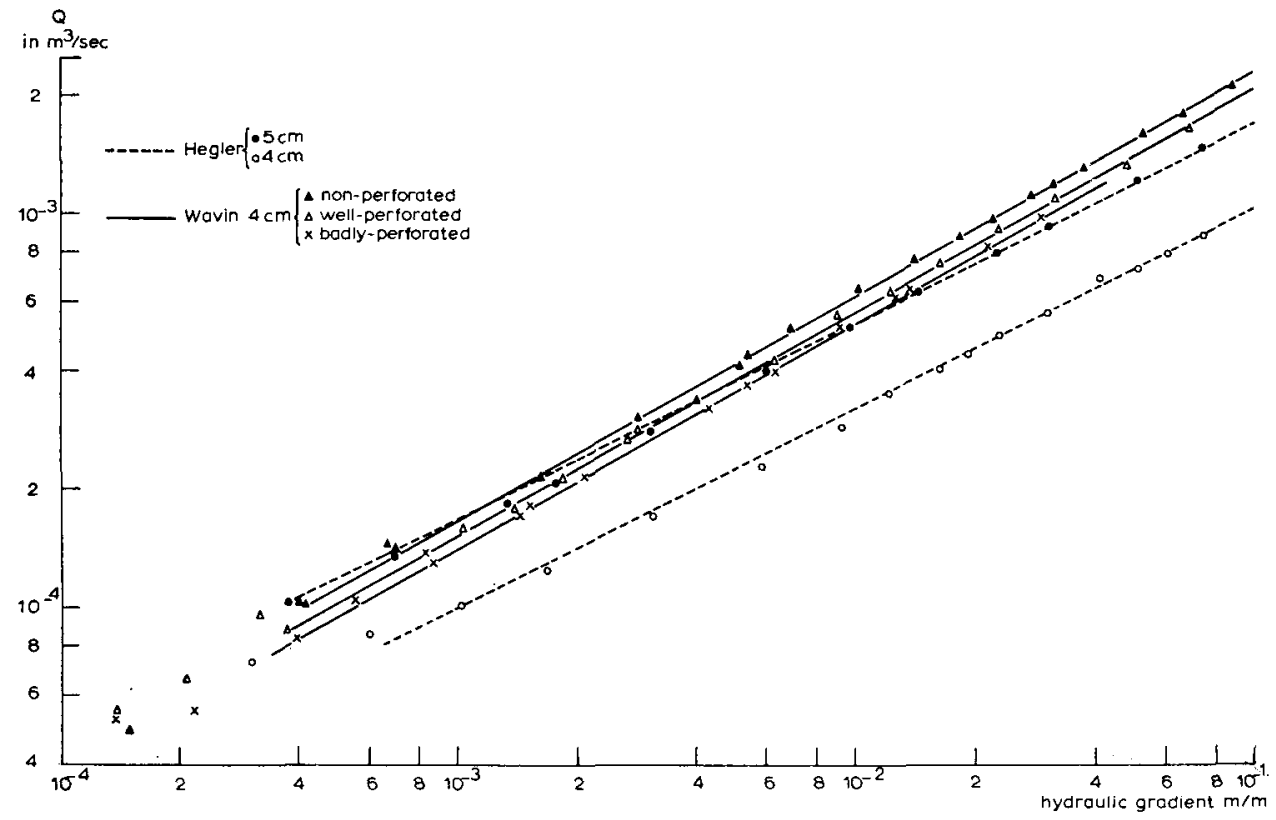

Fig. 5 Relation between experimental discharges and hydraulic gradient for two types of plastic pipes. 
Converting this equation into equation 8 it will give the same results for $S=1.10^{-3}$, the constant then being equal to 73 .

As has already been shown during the discussion of the $\lambda$-values, there is a very good agreement with the data given by Blazhys (1965). Also a close agreement with the formula given by Brink and Nilsson (1965) is found. According to a theory developed by Bretting (1958) different exponents may be found dependent on the range of Reynolds numbers investigated. The differences in exponents found by Visser (1937) and Olbertz and Wertz (1962) may be explained with this theory.

\section{Hydraulic design of drainage lines}

It must be expected that the hydraulic resistance of drain lines increases with age. Further it must be assumed that it increases with silting and poor alignments. Therefore a hydraulic design based on the equations derived above will only be valid under favourable conditions.

For the hydraulic design it is assumed that there exists a constant inflow per unit length of drain rather than a constant flow throughout the whole line. This fact is described by the equation:

$\mathrm{Q}=\frac{\mathrm{q}}{\mathrm{L}}(\mathrm{L}-\mathrm{x})$

where $q$ represents the discharge of the line, $L$ its length and $x$ the distance measured from the outlet.

Taking $\mathbf{S}=\mathrm{dh} / \mathrm{dx}$, substitution of equation 10 into equation 5 gives:

$\left.\left.\frac{\mathrm{dh}}{\mathrm{dx}}=26.3 \times 10^{-4} \mathrm{a}\left(\frac{\mathrm{q}}{\mathrm{L}}\right)\right)^{1.75}(\mathrm{~L}-\mathrm{x})\right)^{1.75} \mathrm{D}^{-4.75}$

Integration and using the condition $\mathrm{h}=0$ for $\mathrm{x}=0$ then gives:

$\mathrm{h}=9.55 \times 10^{-4} \mathrm{a}\left(\frac{\mathrm{q}}{\mathrm{L}}\right)^{1.75}\left\{\mathrm{~L}^{2.75}-(\mathrm{L}-\mathrm{X})^{2.75}\right\} \mathrm{D}^{-4.75}$

Equation 11 now gives the relation between $h$ and $x$ for given $q$ and $L$. This equation will be used to check field data and to work out the data for lateral inflow.

For the hydraulic design the total head loss over a length $\mathrm{x}=\mathrm{L}$ gives the average slope of the drain. Taking $\mathbf{h} / \mathrm{L}=\mathrm{I}$, equation 11 reduces to:

$\mathrm{I}=\frac{\mathrm{h}}{\mathrm{L}}=9.55 \times 10^{-4} \mathrm{a} \mathrm{q}^{1.75} \mathrm{D}^{-4.75}$

Since $\mathrm{q}=\mathrm{s} \mathrm{A}$, with $\mathrm{s}$ representing the design drainage factor and $\mathrm{A}$ the area to be drained, A can be computed for given slope I and diameter D. Some computed values are given in Table 2 for which the measured a-value of 0.35 for well perforated plastic pipes and clay tiles with good alignment is taken.

The diameters pertain to $40 \mathrm{~mm}$ plastic pipe, $50 \mathrm{~mm}$ plastic pipe and $50 \mathrm{~mm}$ clay tiles, respectively. 
Table 2 Maximum area to be drained (in ha) with pipes of three different diameters, with a $=0.35$ for a discharge coefficient of $7 \mathrm{~mm} /$ day

\begin{tabular}{cccc}
\hline $\begin{array}{c}\text { Slope } \\
(\% / 00)\end{array}$ & \multicolumn{3}{c}{ Inner diameter } \\
\cline { 2 - 4 } & $38.2 \mathrm{~mm}$ & $48 \mathrm{~mm}$ & $50 \mathrm{~mm}$ \\
& & & \\
1 & 0.33 & 0.62 & 0.69 \\
2 & 0.50 & 0.92 & 1.02 \\
3 & 0.62 & 1.16 & 1.29 \\
4 & 0.73 & 1.36 & 1.52 \\
\hline
\end{tabular}

Table 3 Maximum area to be drained (in ha) with corrugated pipes of three different diameters for a drainage coefficient of $7 \mathrm{~mm} /$ day

\begin{tabular}{cccc}
\hline \multirow{2}{*}{$\begin{array}{c}\text { Slope } \\
(\% / 00)\end{array}$} & \multicolumn{3}{c}{ Inner diameter } \\
\cline { 2 - 4 } & $36.3 \mathrm{~mm}$ & $41.7 \mathrm{~mm}$ & $44.5 \mathrm{~mm}$ \\
& & & \\
1 & 0.22 & 0.31 & 0.37 \\
2 & 0.31 & 0.44 & 0.53 \\
3 & 0.38 & 0.54 & 0.65 \\
4 & 0.43 & 0.63 & 0.75 \\
\hline
\end{tabular}

Following the same method for corrugated pipes, equations 8 and 10 yield (cf. Wesseling, 1964):

$\mathrm{A}=216.5 \quad 71 \mathrm{D}^{2,67} \mathrm{I}^{1 / 2}$

Computations then give the result represented in Table 3.

\section{Comparison with field data}

Equation 11 can be used to compute the hydraulic head at each $\mathrm{x}$ for given discharge $q$ and length of the line $L$. Two series of field data were available to check the results of the computation ${ }^{4}$. One series of observations pertain to a $150 \mathrm{~m}$ drain line consisting of $50 \mathrm{~mm}$ clay tiles. In this line the hydraulic head was measured at five places. Discharges and corresponding hydraulic heads of two experiments are given in Fig. 6. In this figure the heads computed from equation 11 are also indicated. The measured values turn out to be much higher than the computed ones. By plotting the measured values against the computed data, Fig. 7 is obtained. Apart from minor deviations, the data obey a straight line relationship. This implies that there is a constant ratio between computed and measured values over the whole length of the drain. Therefore the assumption of a constant inflow per unit length of drain is correct. The slope of the obtained line is 0.76 so the actual value of a in the field is $1 / 0.76=1.33$ times the assumed one.

Fig. 8 gives the results of field measurements from a series of $50 \mathrm{~mm}$ plastic drain lines. The data were obtained on the same day from 5 different plastic drain lines. The somewhat larger deviations found here can be due to the inhomogeneities in the soil. Despite that a fairly good straight line relationship is obtained. The slope of the line is 0.64 indicating that the actual a-value is 1.56 times the assumed one.

That the a-value turns out to be higher than that determined from laboratory tests has several reasons. For the clay tile line the alignment may play an important role, for the plastic lines the presence of hairs originating from the material removed by perforating the pipes may be a reason. For both types of pipes silting and age may have had a certain influence. Partial filling of the lines in the upper part did not

4 The authors thank ir. Segeren of the Government Service of the IJsselmeerpolders for providing these data. 
occur as far as could be ascertained. Lateral inflow of water in the lines also could have had a detrimental effect on the apparent roughness of the line. In order to check this, the above mentioned experiments with lateral inflow were planned. From their result it will be seen in the following section that no influence of this could be found, so the larger a-value must for the present be ascribed to the other factors mentioned above.

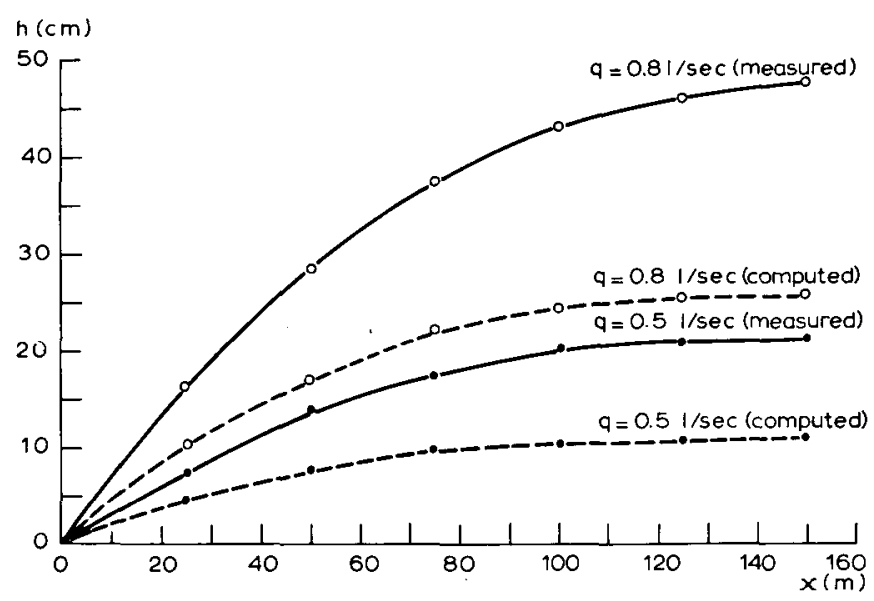

Fig. 6 Field measurements of hydraulic head at two discharges for a $50 \mathrm{~mm}$ clay tile line in the East-Flevopolder (Segeren, 1965, personal communication).

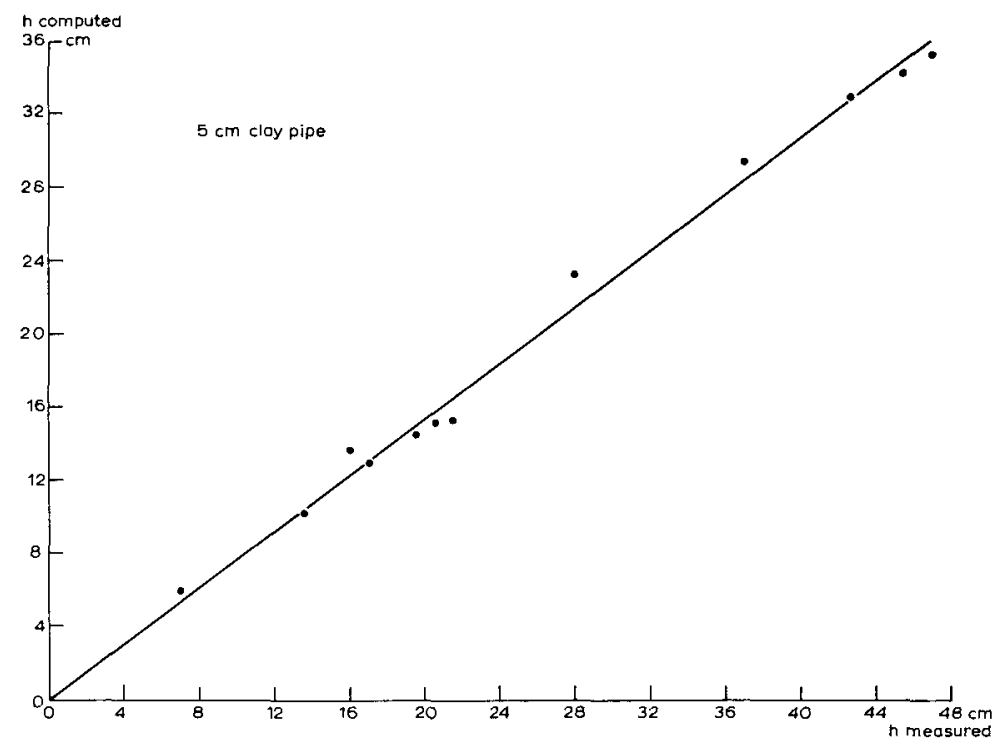

Fig. 7 Computed and measured values of hydraulic head for a $50 \mathrm{~mm}$ clay tile line. 


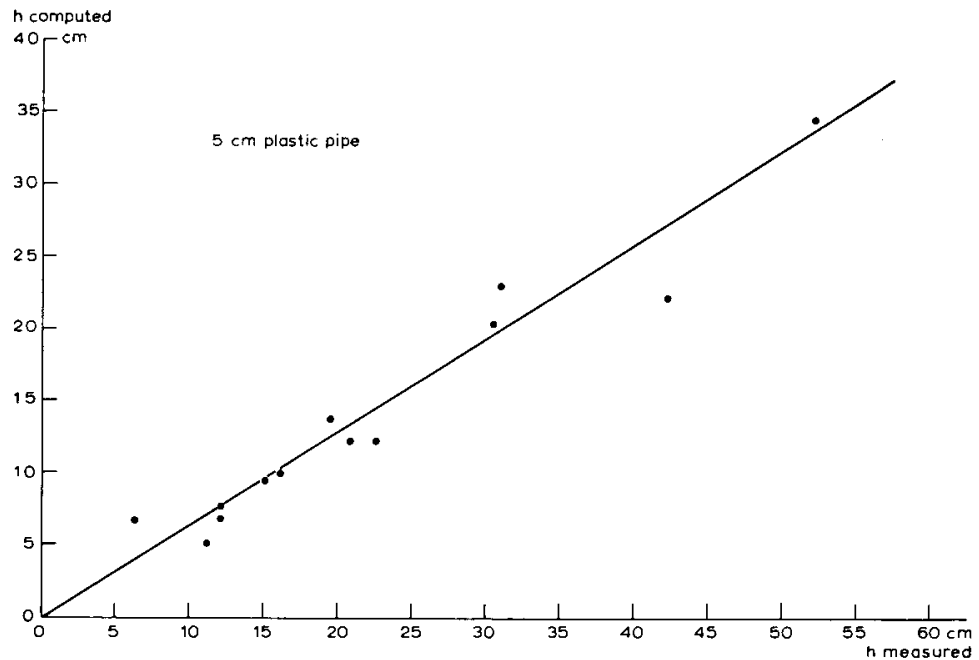

Fig. 8 Computed and measured values of hydraulic head for a $50 \mathrm{~mm}$ plastic drain line in the East-Flevopolder.

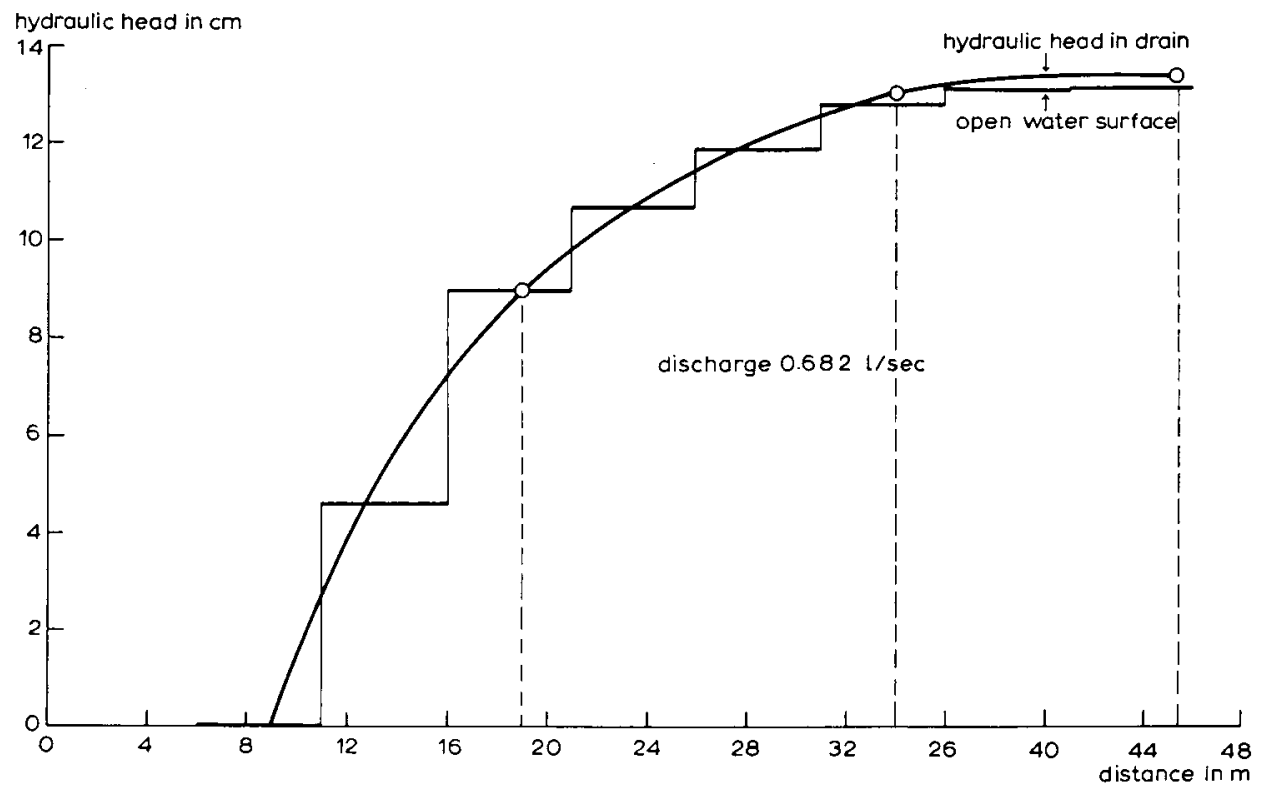

Fig. 9 Measured hydraulic head in the drains and height of the open water table during the experiments with lateral inflow. 


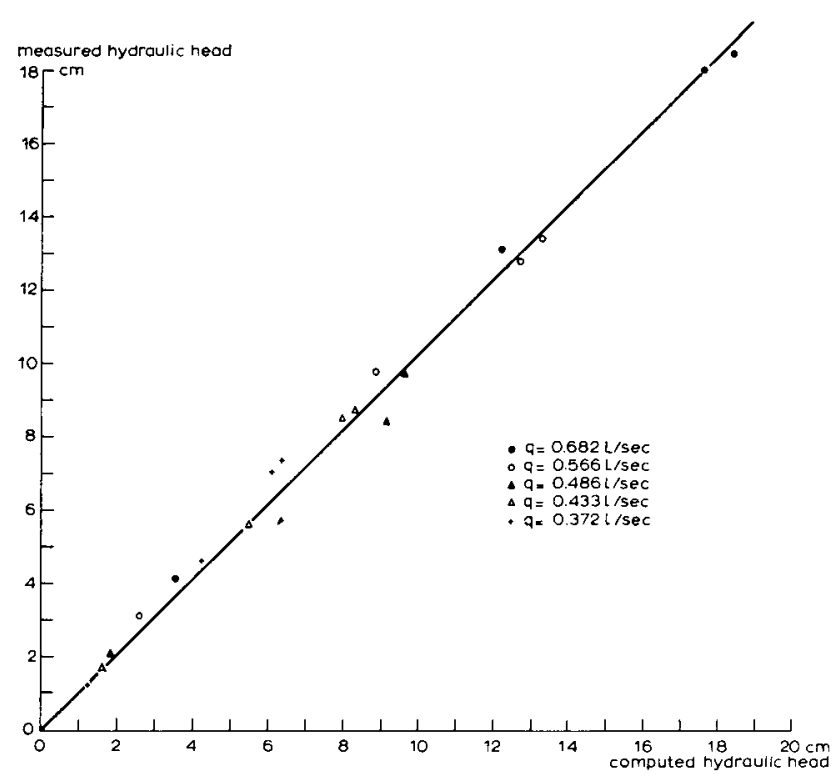

Fig. 10 Measured and computed hydraulic head for experiments with lateral inflow.

\section{The influence of lateral inflow}

In Fig. 9 a typical result of the experiments with lateral inflow, as described under Materials and methods, is given. The hydraulic head at the lower end of the pipe where the perforations ended was used as zero level. Due to the restricted height of the trench walls, the height of the free water surface at the top end could not be brought completely in agreement with the hydraulic head in the drain. Therefore the inflow in this part will have been somewhat too low as compared with that in the remainder of the drain. Similar measurements have been carried out for other discharges. Next, the obtained data were plotted against the computed hydraulic heads for the same discharges. The results are plotted in Fig. 10. The points are fairly well arranged around the $45^{\circ}$ line. The conclusion therefore is, that under the conditions prevailing during the experiments the lateral inflow had no influence on the apparent roughness of the drain.

For the experiments was used a pipe with $900 \mathrm{~mm}^{2}$ perforated area per running meter of drain. For the total length of $40 \mathrm{~m}$ this means an inflow area of $360 \mathrm{~cm}^{2}$. For the highest discharge of $0.6821 / \mathrm{sec}$ the mean flow velocity in the openings amounted to $682 / 360 \mathrm{~cm} / \mathrm{sec}=1.9 \mathrm{~cm} / \mathrm{sec}$. Taking a mean flow of $1 / 2 \times 0.682$ $1 / \mathrm{sec}=0.341 \mathrm{l} / \mathrm{sec}$ in the drain itself, the flow velocity was $27 \mathrm{~cm} / \mathrm{sec}$. Even with the lowest measured discharge of $0.3721 / \mathrm{sec}$ a mean flow velocity of $11.5 \mathrm{~cm} / \mathrm{sec}$ was reached in the drain, which is more than 5 times that in the openings. A possible reason that no influence was found is, that the flow velocities used in the experiments have been too small. Therefore it will be worthwile to investigate to what order of magnitude the flow velocities are under practical conditions. 


\section{Validity of the derived formulas}

It has already been pointed out that the lines representing the relationship between $\lambda$ and $\operatorname{Re}$ tend to flatten out for Reynolds numbers over 70,000. Now the question is, whether the investigated range of Reynolds numbers (up to 60,000) is sufficient to cover all practical cases of drainage. For this purpose Fig. 11 has been constructed. The right hand part of this figure gives the relation between maximum velocity and Reynolds number for 4 different pipe diameters. The left hand upper part relates the maximum velocity with the discharge in $1 / \mathrm{sec}$ and the left hand lower part relates the discharge with the drainage coefficient and the drained area.

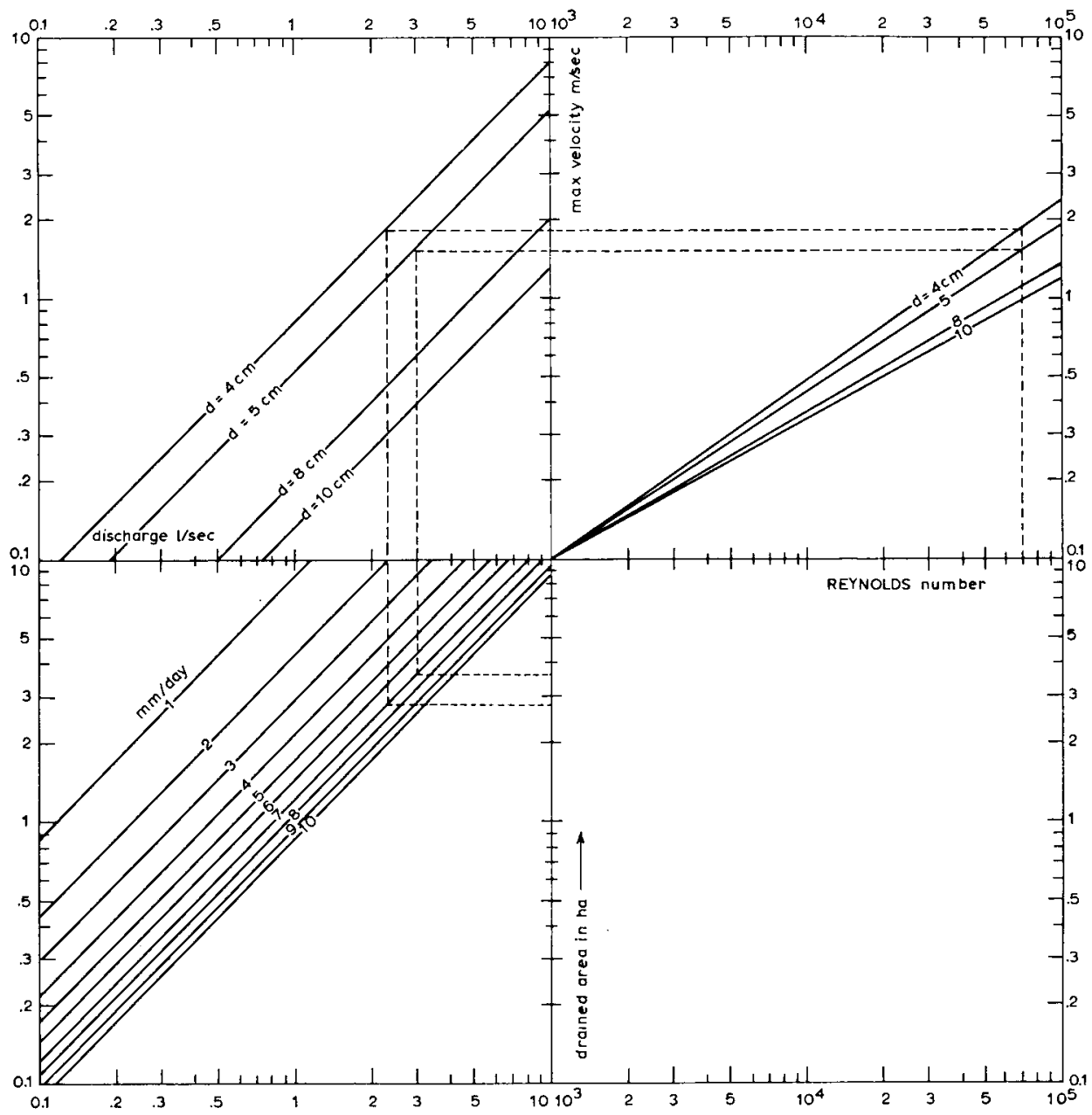

Fig. 11 Nomograph for the relation of Reynolds numbers, maximum flow velocity, discharge, drainage coefficient and drained area in practical drainage cases. 
For a Reynolds number of $7 \times 10^{4}$ (dotted lines in Fig. 11) and a drainage coefficient of $7 \mathrm{~mm} /$ day a drained area of 3.6 ha for a $5 \mathrm{~cm}$ pipe and of 2.8 ha for a $4 \mathrm{~cm}$ pipe is found. On the other hand the maximum drainable areas given in Table 2 are 1.52 and $0.73 \mathrm{ha}$, respectively. If one assumes that these maximum allowable areas are drained, the given Reynolds numbers are only reached when the discharges are $3.6 /(1: 52) \times 7 \mathrm{~mm} /$ day $=16.6 \mathrm{~mm} /$ day and $2.8 / 0.73 \times 7 \mathrm{~mm} /$ day $=26.9$ $\mathrm{mm} /$ day. Field measurements of drain discharges show, however, that such high discharges only rarely occur (cf. Wesseling, 1957; van Hoorn, 1960).

If one takes, on the other hand, the maximum allowable drained area for a design drainage factor of $7 \mathrm{~mm} /$ day one arrives at Reynolds numbers of 19,000 and 10,000, respectively for a $5 \mathrm{~cm}$ and a $4 \mathrm{~cm}$ diameter. Taking into account that these maximum values occur only near the outlet and that in the remainder of the line the Re-numbers will be less, it must be concluded that the experiments cover a sufficient range of Re-numbers.

The experiments with lateral inflow cover discharges from $0.3721 / \mathrm{sec}$ to $0.682 \mathrm{l} / \mathrm{sec}$. For a design coefficient of $7 \mathrm{~mm} /$ day these discharges agree with drained areas of 0.45 and $0.82 \mathrm{ha}$, respectively. This is well within the range of maximum drainable areas for a $4 \mathrm{~cm}$ plastic line given in Table 2 .

\section{References}

Blazhys, B., 1965. Methods of pipe drainage calculations. Proc. Symp. Hydrol. Tech. Probl. Land Drainage, Prague, pp. 143-145.

Bretting, A. E., 1958. A set of practical hydraulic formulae based on recent experimental research. Congr. Intern. Assoc. Hydraulic Structure Res., Stockholm, pp. 7-9-VI.

Brink, N. und Nilsson, S., 1965. Das Leistungsvermögen von Dränrohren aus Kunststoff. Z. Kulturtech., $6: 44-51$.

Hoorn, J. W. van, 1960. Grondwaterstroming in komgrond en de bepaling van enige hydrologische grootheden in verband met het ontwateringssysteem. Thesis, Agric. Univ., Wageningen.

Morris, H. M., 1955. Flow in rough conduits. Trans. Am. Soc. Civil Engrs., 120: 373-398.

Olbertz, M. und Wertz, G., 1962. Hydraulische Versuche zur Bestimmung des Leistungsvermögens von Plastfolienrohren. Z. Landeskultur, 3: 97-111.

Schewior-Press, H., 1958. Hilfstafeln zur Berechnung von Meliorationsentwürfen. Parey, Berlin, 7. Auflage.

Treude, O., 1964. Experimentelle Untersuchungen über die hydraulische Leistungsfähigkeit von Entwässerungsleitungen. Dissertation, Rheinische Friedrich Wilhelm Univ., Bonn.

Visser, W. C., 1937. Wasserbewegung in Dränrohren. Kulturtechniker, 41 : 133-146.

Wesseling, J., 1957. Enige aspecten van de waterbeheersing in landbouwgronden. Thesis, Agric. Univ., Wageningen.

Wesseling, J., 1964. Bepaling van de diameter van drainreeksen. Landbouwk. Tijdschr., 76: 455-464.

Yarnell, D. and Woodward, S., 1920. The flow of water in drain tiles. U.S. Dept. Agr., Bull. 854. 